\title{
논 문
}

\section{코어드 와이어 피딩에 의한 $\mathrm{Cu}$ 용탕에의 합금 첨가 시 효율 평가}

\author{
강복현 * 김기영 \\ 한국기술교육대학교 에너지 · 신소재 · 화학공학부 (*현, (주)에스티아이 C\&D)
}

\section{Evaluation on the Efficiency of Cored Wire Feeding in Addition of Alloying Elements into Cu Melt}

\author{
Bok-Hyun Kang* and Ki-Young Kim ${ }^{\dagger}$ \\ School of Energy, Materials and Chemical Engineering Korea University of Technology and Education, Cheonan 330-708, Korea
}

\begin{abstract}
To add alloying elements into a pure copper melt, the wire-feeding efficiency of cored (alloy containing) wire was evaluated using a commercial, computational fluid-dynamics program. The model design was based on an industrial-scale production line. The variables calculated included wire feed rate, melt temperature, wire diameter, melt flow rate and wire temperature. Efficiency was evaluated after a series of calculations based on the penetration depth of the alloy-wire into the molten copper bath. Of the five variables investigated, the wire feed rate and wire diameter were the most influential factors affecting the feeding efficiency of the cored-wire.
\end{abstract}

Key words : Cored wire feeding, Cu melt, Efficiency, Alloying elements

\section{1. 서 론}

소재산업이 고품질, 환경친화적, 저에너지 소비 기술을 지향 하면서 보다 고효율 공정의 활용이 증가하는 추세에 있다. 철 강이나 비철소재에 있어서도 탈산, 탈황, 개재물 처리 및 합금 화 등과 같은 청정화를 위한 용탕처리 뿐만 아니라 목표하는 합금의 화학조성의 정확한 조절이 요구되고 있다.

분말 원재료를 금속 피복재 등으로 감싸서 와이어의 형태로 만들고 이를 릴에 감은 후 순차적으로 풀어서 용탕에 투입하 는 코어드 와이어(cored wire) 방식은 첨가되는 원재료의 손실 을 최소화하고 높은 효율성을 얻을 수 있는 이점이 있다. 용 강의 탈산을 위한 $\mathrm{Ca}$ 투입 시에도 $\mathrm{Ca}$ 분말을 피복하여 사용 한 경우의 회수율이 높아지고, 미량의 $\mathrm{V}$ 나 $\mathrm{Al}$ 를 합금원소로 참가할 때에도 효율적이라고 보고되고 있다[1-5]. 그리고 코어 드 와이어를 사용할 경우의 용해메커니즘에 대한 모델 및 열 전달에 관한 연구도 보고된 바 있다[6-9]. 또한 철강산업에서
뿐만아니라 주철 제조 시에도 코어드 와이어법이 이용되고 있 는데, 주철의 구상화처리[10], 선철의 탈황[11] 등에서도 활용 이 되고 있다.

한편, 비철산업에서는 코어드 와이어법이 아직 활발히 채용이 되지 않고 있는 상태이나, 전자부품용 동합금 소재와 같이 정 밀한 합금화가 필요하거나 산화가 용이하여 분말로 첨가 시 회수율이 낮은 원소의 합금 시 그 활용이 기대되고 있다. 실 제 정확한 장입계산으로 합금원소를 투입하더라도 최종 목표 조성을 관리하는 것은 쉽지 않다. 특히 산화가 쉬운 원소의 경우 용탕에 투입했을 때 회수율의 변동성이 심하고, 마이크로 합금화(micro alloying)와 같이 첨가량이 매우 적다면 화학조성 의 조절이 더욱 어렵고, 회수율의 예측 또한 힘들다.

일반적으로 동합금의 제조 시 합금원소는 용해라인에서 연속 적으로 첨가되는데, 기존 공정라인에서의 합금화는 배합로에서 합금원소를 덩어리 또는 분말 형태로 투입하여 진행한다. 그러 나 이러한 배합방식은 많은 양의 분진 발생으로 작업환경을

Received: Sep. 27, 2013 ; Revised: Dec. 10, 2013 ; Accepted: Dec. 17, 2013 Journal of Korea Foundry Society 'Corresponding author: Ki-Young Kim (Korea Univ of Tech. and Edu.) 2013. Vol. 33 No. 6, pp. 248 253

Tel: +82-41-560-1323, Fax: +82-41-560-1360

http://dx.doi.org/10.7777/jkfs.2013.33.6.248

E-mail: simha@kut.ac.kr pISSN 1598-706X / eISSN 2288-8381

(C) Korea Foundry Society, All rights reserved.

This is an Open-Access article distributed under the terms of the Creative Commons Attribution Non-Commercial License (http://creativecommons.org/licenses/by-nc/3.0) which permits unrestricted non-commercial use, distribution, and reproduction in any medium, provided the original work is properly cited. 
나쁘게 하고, 특히 분말의 상태로 용탕과 접촉하므로 산화가 용이하여 회수율의 변동이 심한 단점이 있다.

동합금 제조에 있어서 코어드 와이어법의 적용에 대한 실험 실적 연구는 수행된 바 있으나[12], 다양한 공정변수를 고려하 기 위해서는 실제 동합금의 용해, 연주 라인에서 실험하는 것 은 어려우므로, 전산모사를 활용하여 각 변수의 영향을 알아보 는 것도 효과적인 방법 중의 하나이다.

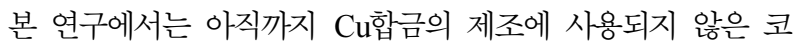
어드 와이어 피딩법의 전산모사를 통하여 와이어 피딩 시의 효율에 미치는 공정변수의 영향을 조사하였다.

\section{2. 연구 방법}

Fig. 1은 용해라인에서의 와이어 피딩 모식도를 나타낸 것으 로, 배합로에서 합금을 투입한다고 가정하였다. 또한 용탕의 유 속은 연주되는 슬라브의 유량과 용탕유로의 단면적으로 유로 내에서의 용탕유속을 산출하였고, 이러한 용탕의 흐름을 가정하 여 유체의 $\mathrm{X}+$ 방향으로의 유속을 정의하였다. Fig. 2는 계산모 델을 나타낸 것으로 $100 \times 500 \times 20 \mathrm{~mm}$ 크기의 모델을 길이 방향으로 50 개, 높이 방향으로 250 개, 두께 방향으로 10 개의

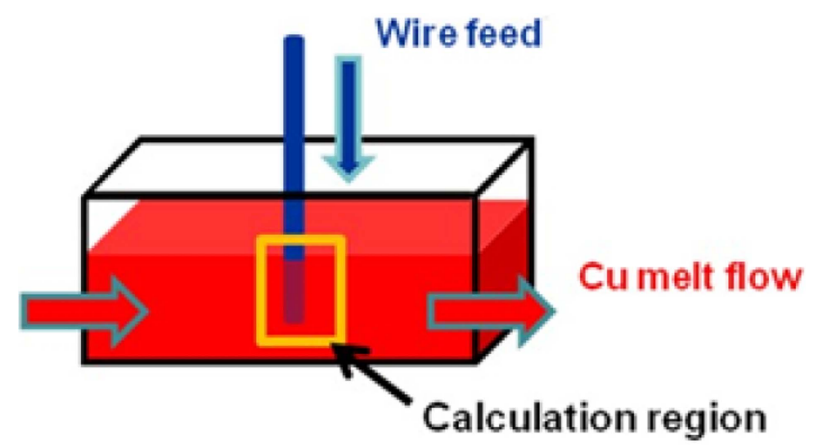

Fig. 1. Schematic of wire feeding in a melting line.

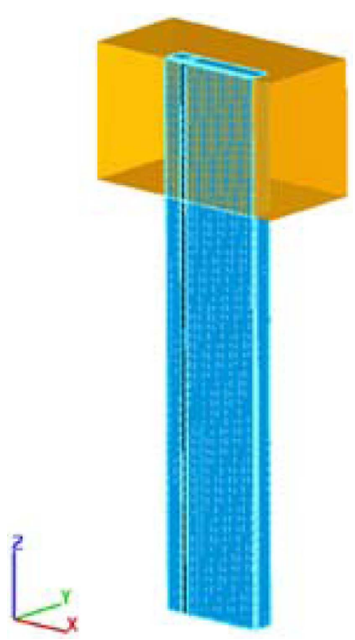

Flg. 2. Three dimensional model for wire feeding simulation.
Table 1. Material properties used for calculation.

\begin{tabular}{ccc}
\hline Phase & Property & Value \\
\hline \multirow{4}{*}{ Fluid } & Density, $\mathrm{kg} / \mathrm{m}^{3}$ & 8,020 \\
(Molten copper) & Viscosity, Pa.s & $4.5 \times 10^{-4}$ \\
& Specific heat, J/kg.K & 494.5 \\
& Thermal conductivity, W/m.K & 166 \\
\hline & Density, $\mathrm{kg} / \mathrm{m}^{3}$ & 5,352 (Pure copper : \\
& Specific heat, J/kg.K & $8,920)$ \\
Solid & Thermal conductivity, W/m.K & 385 \\
(Cored wire) & Liquidus temp., K & 1,356 \\
& Solidus temp., K & 1,356 \\
& Latent heat of fusion, $\mathrm{J} / \mathrm{kg}$ & $2.05 \times 10^{5}$ \\
\hline
\end{tabular}

Table 2. Calculation variables.

\begin{tabular}{cc}
\hline Variables & Value \\
\hline Wire injection velocity & $5,7,10,12 \mathrm{~m} / \mathrm{min}$ \\
Melt temperature & $1448,1498,1523 \mathrm{~K}$ \\
Wire diameter & $6,8,12 \mathrm{~mm}$ \\
melt flow rate & $1.5,1.7,2.1 \mathrm{~m} / \mathrm{min}$ \\
Wire temperature & $303,333,363 \mathrm{~K}$ \\
\hline
\end{tabular}

요소로 나누었다. 용탕은 순 $\mathrm{Cu}$ 로 가정하였고, 와이어의 재질 은 $\mathrm{Cu}$ 이며, 튜브 안에 $\mathrm{Cu}$ 분말이 들어 있는 것으로 가정하였 다. 계산상 합금분말은 정의가 안 되기 때문에, 코어드 와이어 의 밀도는 벌크 재질 밀도의 $60 \%$ 의 밀도로 입력하였다. 계산 에 사용한 재질별 물성은 Table 1과 같다. 용탕의 흐름, $\mathrm{Cu}$ 용 탕과 와이어 사이의 열이동은 상용 유체해석 소프트웨어인 Flow-3D를 이용하여 3차원 계산을 수행하였다.

계산변수는 와이어의 송급속도, 용탕의 온도, 와이어의 직경, 용탕의 흐름속도 및 와이어의 온도로 하였으며, 상세는 Table 2 와 같다. 와이어의 송급속도는 Z-방향으로 당겨지는 것으로 입력하였다.

\section{3. 결과 및 고찰}

\section{1 전산모사 결과의 평가 기준}

계산의 효율성을 위하여 본 계산에 앞서 2차원 모델 계산을 통하여 공정변수에 따른 전산모사 결과에 대한 평가 기준을 설정하였다. Fig. 3은 $1,473 \mathrm{~K}$ 용탕 내에 직경 $6 \mathrm{~mm} \mathrm{Cu}$ 와 이어를 $10 \mathrm{~m} / \mathrm{min}$ 의 속도로 송급하였을 때의 계산결과를 고상 율로 나타낸 것인데, 시간에 따라 고상분율이 변하는 것을 볼 수 있다. 송급 초기, 와이어가 송급속도에 따라 하강하다 일정 깊이에 도달한 이후에는 시간이 증가하여도 침투깊이가 증가하 지 않는데, 이는 정상상태에 돌입한다는 것을 의미한다. 즉 송 급 시간을 길게 하여도 와이어가 녹아버리므로 와이어의 침투 깊이는 더 이상 증가하지 않는다는 것이다. 와이어의 침투 및 


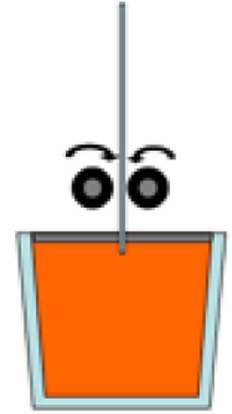

I

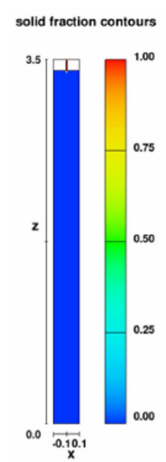

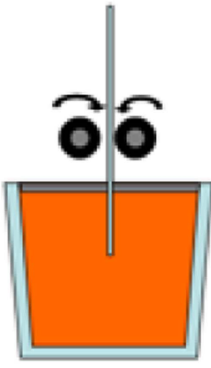

II

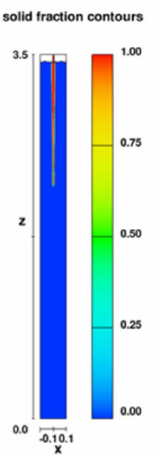

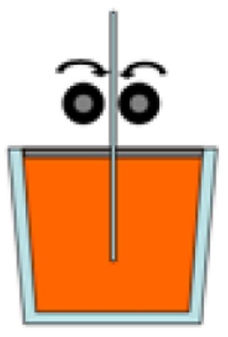

III

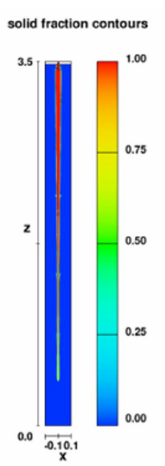

Fig. 3. Change in solid fraction of the cored wire during feeding: (I) initial heating, (II) transient melting, (III) steady state melting.

용해과정은 이전 연구[9]에서 용강 중에 $\mathrm{Ti}$ 와이어를 송급할 때와 거의 유사한 결과를 나타내었는데, 요약하면 초기용융단계, 비정상용융단계, 정상용융단계의 3단계로 구분할 수 있다. 초기 용융단계는 초기에 와이어 송급 장치에 의하여 일정한 속도로 와이어가 용탕에 주입되는 단계로, 주입된 와이어는 일정한 속
도로 하강하면서 고온의 용탕에 의하여 가열되므로 온도가 상 승된다. 이 단계에서는 Fig. 3에서 알 수 있는 바와 같이 용 탕 중으로 약간 내려간 와이어의 고상율은 1 로 원래의 형태를 유지하고 있다. 비정상 용융단계에서는 용탕에 노출되는 시간이 길어지므로 와이어의 온도가 상승하여 합금분말을 감싸고 있는 피복재가 용융되어 내부의 합금분말이 용탕에 노출된다. 그러나 피복재의 용융속도보다 와이어의 송급속도가 빨라 와이어는 형 태를 갖추고 계속 하강하는 단계이다. 이 단계에서 와이어의 고상율은 아직 1 부근이다. 정상 용융단계에 이르면 와이어의 용해속도와 송급속도가 같아지는 단계로 와이어의 온도가 피복 재의 완전 용해온도까지 상승하여 와이어는 더 이상 용탕 중 으로 내려가지 못한다. 또한 피복재가 더 이상 보호관로써의 역할을 하지 못하여 내부의 합금분말이 용탕에 완전히 노출되 어 용탕과의 반응이 활발히 일어나는 단계이다. 이 단계에서는 와이어의 끝부분의 고상율은 0.5 미만이어서 와이어가 일정 깊 이 침투 후에는 용탕에 녹아 들어감을 알 수 있다.

이상으로부터 공정변수에 따른 전산모사 결과로 와이어 피딩 법의 효율을 평가하기 위하여 와이어 침투깊이를 기준으로 하 였는데, 와이어의 침투깊이는 고상율이 0.7 로 되는 지점으로 하였다. 즉 용탕 중에 와이어를 넣었을 때 용탕 표면 부근에 서 용해가 되면 그 때의 와이어의 회수율은 낮아지고, 깊이 들어가면 회수율이 높아진다고 가정하면, 용탕에의 침투 깊이는 와이어의 회수율을 나타내는 간접적인 지표가 될 수 있다는 것이다.

\section{2 공정변수의 영향}

Fig. 4는 용탕온도 $1,473 \mathrm{~K}$, 와이어직경 $10 \mathrm{~mm}$, 용탕흐름 속도 $1.7 \mathrm{~m} / \mathrm{s}$, 와이어 온도 $303 \mathrm{~K}$ 일 때, 와이어의 송급속도에 따른 와이어의 용해 상황을 정상상태에 도달하였을 때의 고상 율로 나타낸 것이다. 그림에서 바늘과 같은 직선부위는 아직
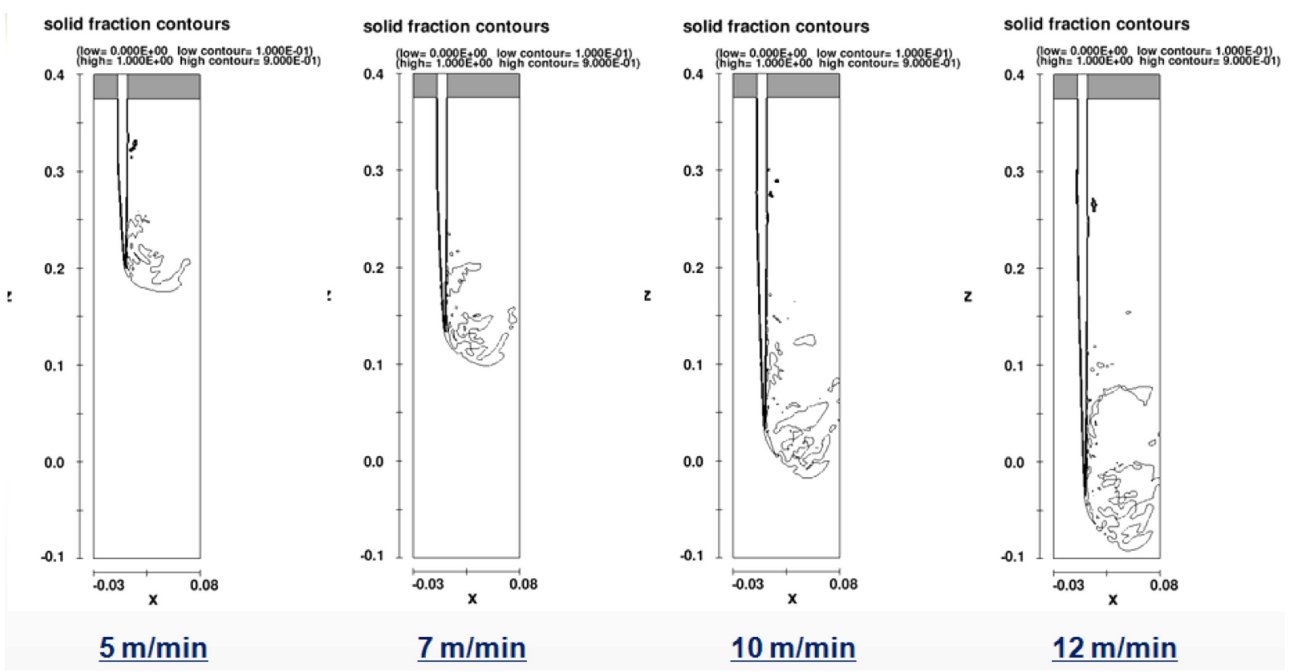

Fig. 4. Solid fraction contours with wire feed rate at steady state: melt temp. $1473 \mathrm{~K}$, wire dia. $10 \mathrm{~mm}$, melt flow rate $1.7 \mathrm{~m} / \mathrm{s}$, wire temp. $303 \mathrm{~K}$. 


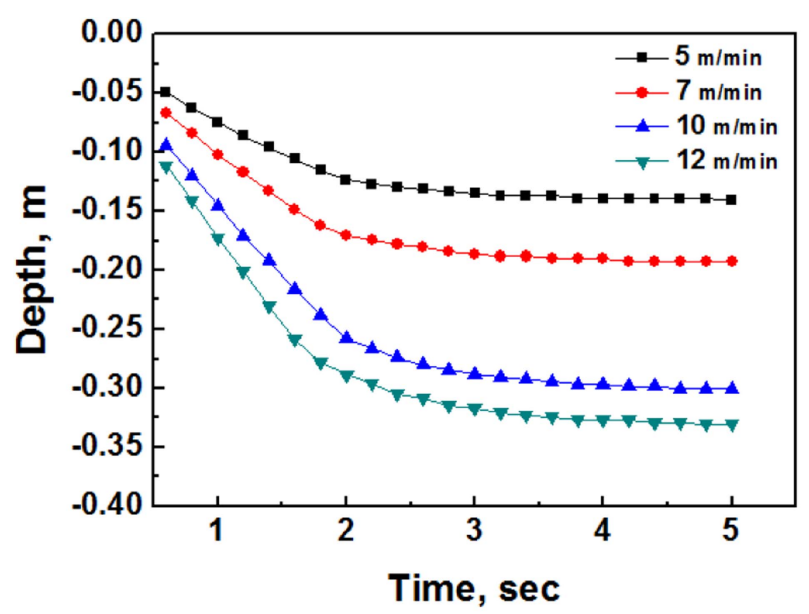

Fig. 5. Effect of wire feed rate on the penetration depth of wire at its solid fraction of 0.7 .

고상율이 0.7 보다 높은 상태이어서 와이어가 고체형상을 유지 하고 있다. 오른쪽의 퍼진 부분은 고상율이 영에 가까운 부분 으로 와이어의 일부가 용탕 중으로 녹아 들어가는 것을 나타 낸다. 용탕은 정지상태가 아니고 그림의 왼쪽에서 오른쪽으로 연속하여 흐르고 있으므로 녹은 와이어는 오른쪽 방향으로 흩 어짐을 볼 수 있다. Fig. 5 는 와이어의 송급속도에 따른 와이 어 침투깊이의 시간변화를 나타낸 것으로, 시간의 경과에 따라 서 초기에는 침투깊이가 증가하나, 2 3초 사이의 구간에서 시 간의 증가에 따른 변화가 완만해짐을 알 수 있다. 즉 정상상 태에 도달하는 것을 알 수 있는데, 송급속도가 빠를수록 정상 상태에 도달하는 시간은 길어지고 있다. 송급속도가 빨라지면 와이어의 침투깊이가 깊어지는데, 와이어가 용해되는데 필요한 열량이 동일하다고 보면, 용탕으로부터 와이어로의 열전달속도 가 작아지므로 더 깊은 곳까지 그 형상을 유지하기 때문이다.
Fig. 6 은 송급속도 $7 \mathrm{~m} / \mathrm{s}$, 와이어 직경 $10 \mathrm{~mm}$, 용탕흐름 속 도 $1.7 \mathrm{~m} / \mathrm{s}$, 와이어 온도 $303 \mathrm{~K}$ 일 때, 용탕온도에 따른 와이 어의 용해 상황을 정상상태에 도달하였을 때의 고상율로 나타 낸 것이다. 용탕온도가 높을수록 와이어의 침투깊이는 감소함을 볼 수 있다. 이는 용탕온도가 높을수록 용탕이 가진 열량이 크 므로 그만큼 빠르게 용탕으로부터 와이어로의 열전달이 이루어 지기 때문이다.

Fig. 7 은 송급속도 $7 \mathrm{~m} / \mathrm{s}$, 용탕온도 $1,473 \mathrm{~K}$, 용탕흐름 속도 $1.7 \mathrm{~m} / \mathrm{s}$, 와이어 온도 $303 \mathrm{~K}$ 일 때, 와이어의 직경에 따른 와 이어의 용해 상황을 정상상태에 도달하였을 때의 고상율로 나 타낸 것이다. 와이어의 직경이 굵을수록 와이어의 침투깊이는 현저하게 증가함을 볼 수 있다. 이는 용탕으로부터 와이어로의 열전달 속도가 동일하다고 보면, 와이어의 직경이 크면 와이어 의 용해에 필요한 열량이 증가하므로 그만큼 오래 와이어의 형상을 유지할 수 있기 때문이다. Fig. 8을 보면 와이어의 굵 기가 $6 \mathrm{~mm}$ 일 경우는 용탕에 들어가자 마자 용해가 됨을 알 수 있는데 이러한 경우는 첨가하고자 하는 원소가 용해된 후 상부로 부상하여 슬래그 중으로 들어갈 가능성이 많으므로, 첨 가하고자 하는 합금의 회수율은 매우 낮아질 것으로 보인다.

Fig. 9는 용탕 흐름속도에 따른 와이어의 침투깊이인데, 속도 의 증가에 따라서 침투깊이는 약간 증가하고 있다. 와이어와 용탕 간의 접촉 열전달로 인하여 와이어와 접촉해있는 용탕의 온도는 약간 내려가고, 와이어의 온도는 올라가는데 용탕이 정 지 상태가 아니라 계속 흘러가고 있으므로 와이어의 표면에는 새로운 용탕이 접촉하게 되는데, 본 연구의 조건 하에서는 큰 차이를 나타내지 않았다.

Fig. 10 은 와이어 초기온도 따른 와이어의 침투깊이인데, 와 이어 온도의 증가에 따라서 침투깊이는 별 차이를 보이지 않 고 있다. 와이어의 초기온도는 $303 \mathrm{~K}$ 에서 $363 \mathrm{~K}$ 까지로 하였는 데 이정도의 온도 차이는 용탕의 온도와 비교하여 매우 낮은

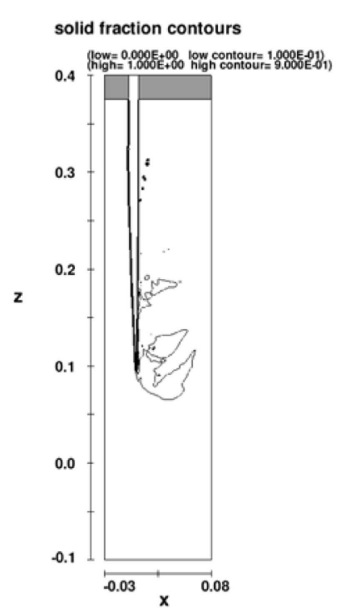

$1448 \mathrm{~K}$

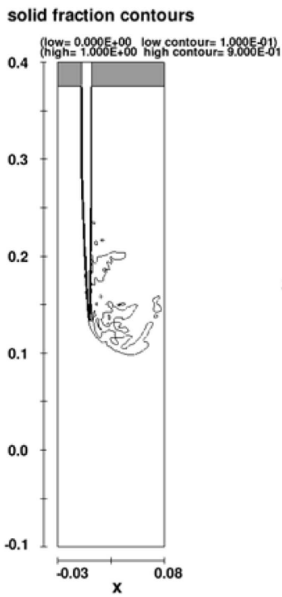

$1473 \mathrm{~K}$

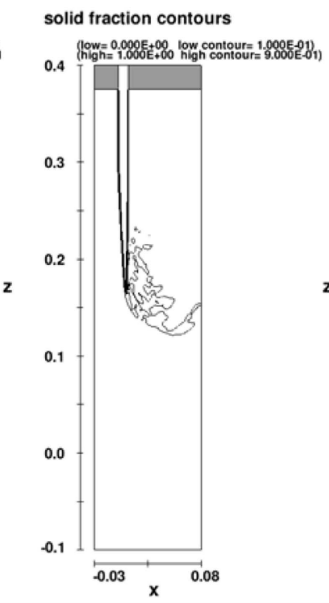

$1498 \mathrm{~K}$

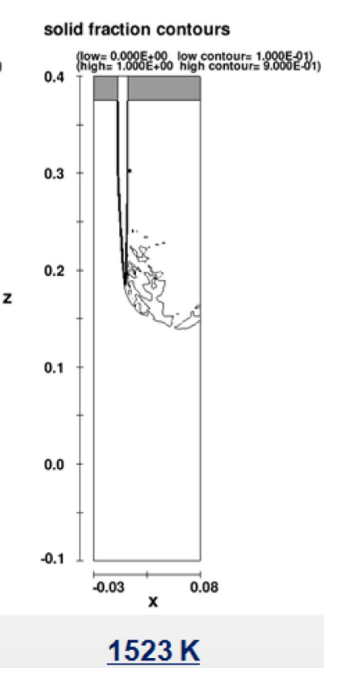

Fig. 6. Solid fraction contours with melt temperature at steady state: wire feed rate $7 \mathrm{~m} / \mathrm{s}$, wire dia. $10 \mathrm{~mm}$, melt flow rate $1.7 \mathrm{~m} / \mathrm{s}$, wire temp. $303 \mathrm{~K}$. 


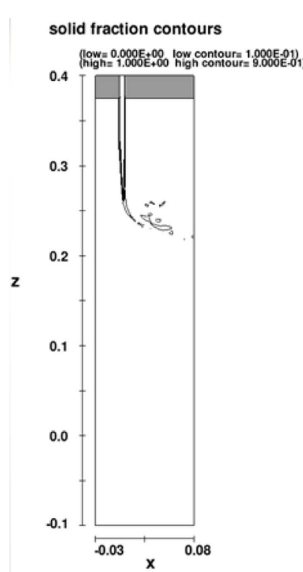

$\underline{6 \mathrm{~mm}}$

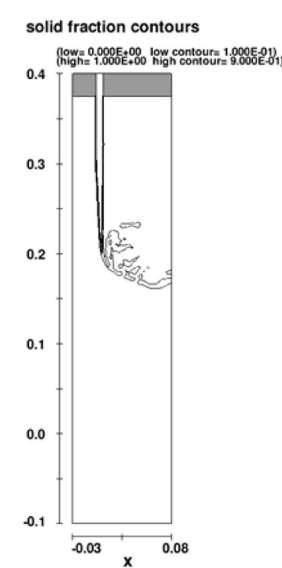

$8 \mathrm{~mm}$

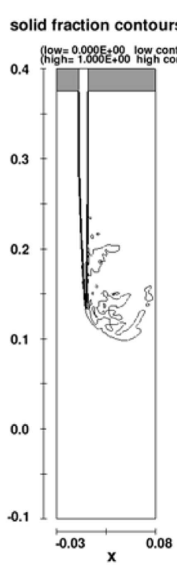

$10 \mathrm{~mm}$

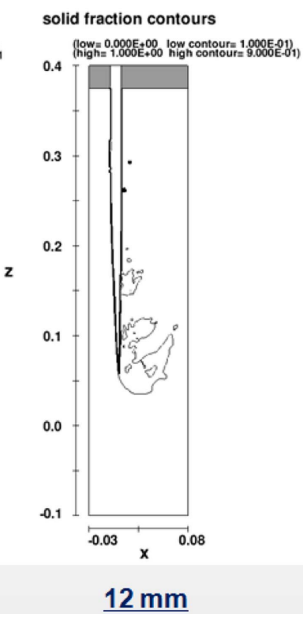

Fig. 7. Solid fraction contours with wire diameter at steady state: wire feed rate $7 \mathrm{~m} / \mathrm{s}$, melt temp. $1473 \mathrm{~K}$, melt flow rate $1.7 \mathrm{~m} / \mathrm{s}$, wire temp. $303 \mathrm{~K}$.

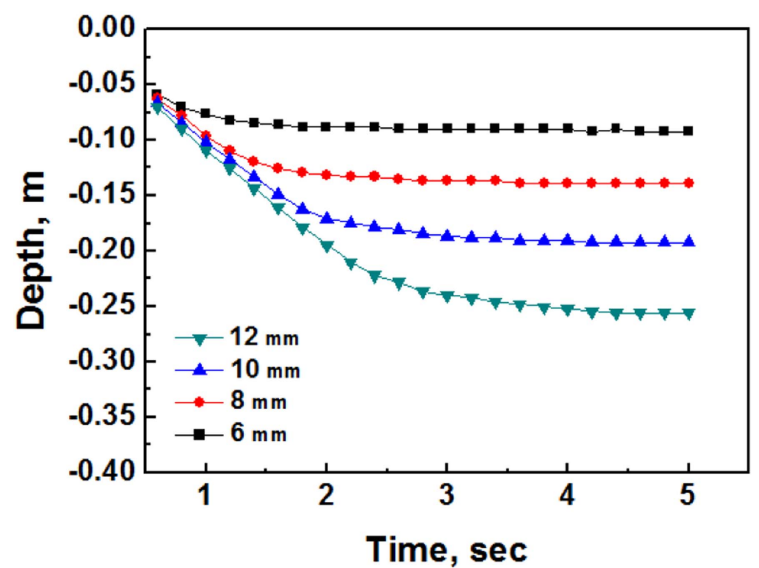

Fig. 8. Effect of wire diameter on the penetration depth of wire at its solid fraction of 0.7 .

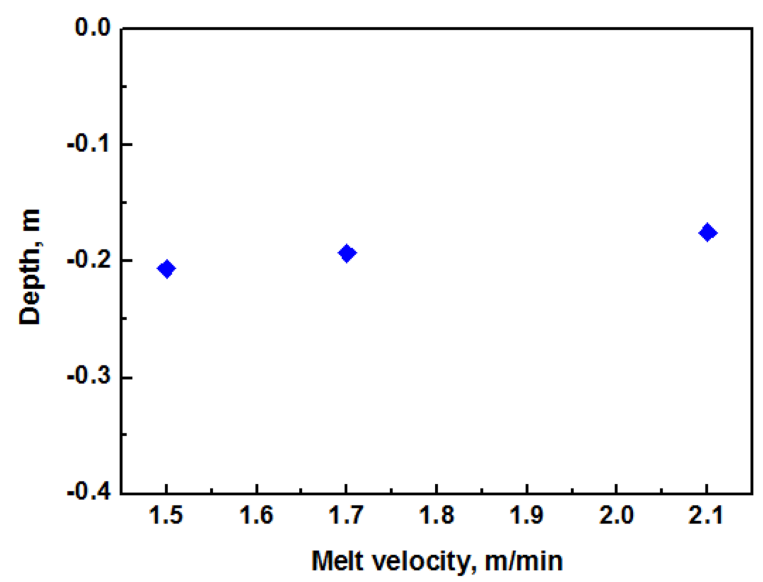

Fig. 9. Effect of melt flow rate on the penetration depth of wire.

온도이므로 와이어의 용해에 큰 영향을 끼치지 않은 것으로 보인다.

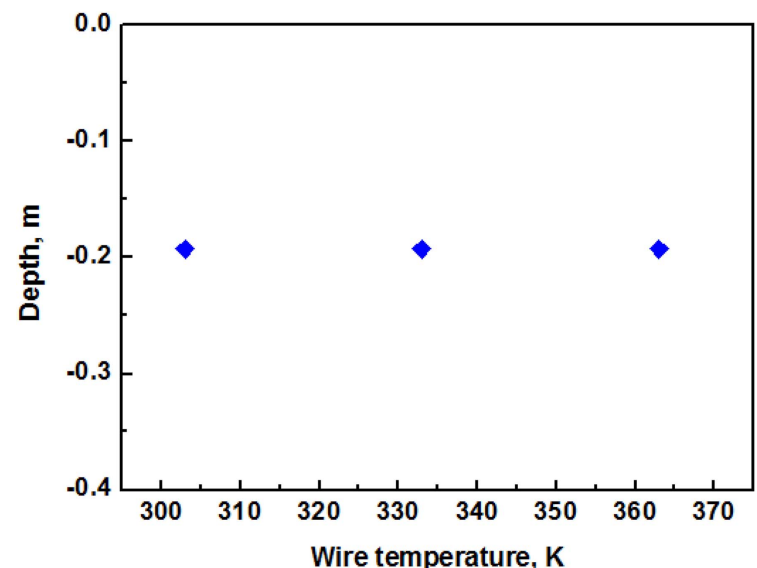

Fig. 10. Effect of wire temperature on the penetration depth of wire.

앞서와 같이 계산변수로 와이어의 송급속도, 용탕의 온도, 와 이어의 직경, 용탕의 흐름속도 및 와이어의 온도로 하여 와이 어의 침투깊이를 계산하고 나서, 각 변수의 영향을 평가하기 위하여 중회귀분석을 실시한 결과는 다음과 같다.

Penetration depth of wire $=-0.0245 \times$ wire feed rate + $0.0006 \times$ melt temp. $-0.0249 \times$ wire diameter $+0.0080 \times$ melt flow rate $-0.4985\left(r^{2}=0.93\right)$

위식을 보면 5 개의 변수 중 와이어의 송급속도와 와이어의 직경이 와이어의 침투 깊이에 가장 영향이 큰 것으로 나타났 다. 즉 와이어가 용탕의 상면 가까이에서 용해되어 버리면 산 화가 용이하게 되고 부상하여 슬래그 중으로 들어가 버리므로 효율이 떨어지나, 용탕의 저부에서 용해되면 대부분 $\mathrm{Cu}$ 용탕 중 으로 녹아 들어가므로 첨가하는 합금원소의 회수율이 높아지게 됨을 기대할 수 있다. 


\section{4. 결 론}

코어드 와이어 피딩 공정을 와이어의 송급속도, 용탕의 온도, 와이어의 직경, 용탕의 흐름속도 및 와이어의 온도를 공정변수 로 하여 전산모사하고, 피딩공정의 효율은 와이어의 침투 깊이 로 평가하였다. 그 결과, 와이어의 송급속도와 와이어의 직경이 와이어의 침투 깊이에 가장 영향이 큰 것으로 나타났다. 즉 와이어가 용탕의 상면 가까이에서 용해되어 버리면 산화가 용이 하게 되고 부상하여 슬래그 중으로 들어가기 쉬우므로 효율이 떨어지나, 용탕의 저부에서 용해되면 대부분 $\mathrm{Cu}$ 용탕 중으로 녹 아 들어가므로 첨가하는 합금원소의 회수율이 높아지게 됨을 기 대할 수 있다. 연속주조라인에서는 빌렛의 최종 조성의 조절이 중요한데, 와이어의 직경과 적정 송급속도의 조화가 필요하다.

\section{감사의 글}

본 연구는 지식경제부 중기거점과제 및 한국기술교육대학교 교내 연구비 지원으로 수행되었으며, 관련 공정에 대하여 많은 조언을 주신 (주) 풍산의 황인엽박사와 조영래과장께 감사드립 니다.

\section{References}

[1] P. Murray, Metallurgist, "Use of cored wire to introduce metallic powders into molten metal”, 41 (1997) 53-55.

[2] S. Basak, R. Kumar Dhal and G. G. Roy, Ironmaking and Steelmaking, "Efficacy and recovery of calcium during $\mathrm{CaSi}$ cored wire injection in steel melts", 37 (2010) 161-168.

[3] D.A. Dyudkin, V.V. Kisilenko, V.P. Onishchuk, A.A. Larionov, and B.V. Neboga, Metallurgist, "Effectiveness of alloying steel with vanadium from cored wire", 46 (2002) 203-204.

[4] Y. Heikiki and M. Juha, Scandinavian J. of Metallurgy, "Steel composition adjustment by wire feeding at Rautaruukki Oy Raaha steel works", 19 (1990) 142-145.

[5] S.V. Kazakov, A.A. Neretin, S.M. Chumakov, S.D. Zinchenko and A. B. Lyatin, Metallurgist, "Treatment of converter steel with calcium-aluminum wire", 42 (1998) 173-175.

[6] S. Sanyal, S. Chandra, S. Kumar and G.G. Roy, Steel Research Int., "Dissolution kinetics of cored wire in molten steel", 77 (2006) 541-549.

[7] S. Sanyal, S. Chandra, S. Kumar and G.G. Roy, ISIJ Int., "An Improved Model of Cored Wire Injection in Steel Melts", 44 (2004) 1157-1166.

[8] S. Sanyal, J.K. Saha, S. Chandra and C. Bhanu, ISIJ Int., "Model based optimazation of aluminum wire injection in steel melts", 46 (2006) 779-781.

[9] M.G. Kim, D.C. Hwang, J.J. Choi, S.Y. Yoon, B.J. Ye, J.H. Kim and W.B. Kim, J. KFS, "Heat Flow Analysis of Ferritic Stainless Steel Melt during Ti wire feeding”, 29 (2009) 277 283.

[10] I. Ruiz, F. Wolfsgruber and J. L. Enriquez, Inter. J. of Cast Metals Research, "Production of ductile iron with the cored wire technology", 16 (2003) 7-10.

[11] A.M. Zborshchik, Metallurgist, "Cost-effectiveness of desulfurizing pig iron with magnesium-bearing cored wire", 45 (2001) 360-362.

[12] B.H. Kang, W.H. Lee, J.Y. Cho, M.J. Lee and K.Y. Kim, Advanced Mater. Reasearch, "Yield of alloying elements fed by cored wire into a copper melt", 690-693 (2013) 62-65. 